\title{
Diffusion-Weighted Magnetic Resonance Imaging in the Diagnosis of Cerebral Venous Thrombosis : A Meta-Anal- ysis
}

\author{
Bin Lv, ${ }^{1, *}$ Feng Jing, ${ }^{1, *}$ Cheng-lin Tian, Jian-chao Liu, ${ }^{2}$ Jun Wang, ${ }^{1}$ Xiang-yu Cao, ${ }^{1}$ Xin-feng Liu, ${ }^{1}$ Sheng-yuan Yu \\ Department of Neurology, Chinese PLA General Hospital, Beijing, China \\ Department of Medical Statistics, ${ }^{2}$ Chinese PLA General Hospital, Beijing, China
}

Objective : A role of diffusion-weighted imaging (DWI) in the diagnosis of cerebral venous thrombosis (CVT) is not wellunderstood. This study evaluates the effectiveness of DWI in the diagnosis of CVT.

Methods : Literature search was conducted in electronic databases for the identification of studies which reported the outcomes of patients subjected to DWI for CVT diagnosis. Random-effects meta-analyses were performed to achieve overall estimates of important diagnostic efficiency indices including hyperintense signal rate, the sensitivity and specificity of DWI in diagnosing CVT, and the apparent diffusion coefficient (ADC) of DWI signal areas and surrounding tissue.

Results : Nineteen studies (443 patients with 856 CVTs; age 40 years [95\% confidence interval (Cl), 33 to 43]; 28\% males [95\% Cl, 18 to 38]; symptom onset to DWI time 4.6 days [ $95 \% \mathrm{Cl}, 2.3$ to 6.9]) were included. Hyperintense signals on DWI were detected in $40 \%$ $(95 \% \mathrm{Cl}, 26$ to 55$)$ of the cases. The sensitivity of DWI for detecting CVT was $22 \%(95 \% \mathrm{Cl}, 11$ to 34$)$ but specificity was $98 \%(95 \% \mathrm{Cl}$, 95 to 100). ADC values were quite heterogenous in DWI signal areas. However, generally the ADC values were lower in DWI signal areas than in surrounding normal areas (mean difference $-0.33 \times 10^{-3} \mathrm{~mm}^{2} / \mathrm{s}[95 \% \mathrm{Cl},-0.44$ to -0.23$] ; p<0.00001$ ).

Conclusion : DWI has a low sensitivity in detecting CVT and thus has a high risk of missing many CVT cases. However, because of its high specificity, it may have supporting and exploratory roles in CVT diagnosis.

Key Words : Thrombosis, Cerebral venous · Magnetic resonance imaging, Diffusion weighted · Diagnosis · Specificity · Sensitivity.

\section{INTRODUCTION}

Cerebral venous thrombosis (CVT) is a distinct cerebrovascular disease which accounts for approximately $1-2 \%$ of all adult stroke cases $^{19)}$. It has an annual incidence of $3-4$ cases per million in adults and up to seven cases per million in children $^{30)}$. CVT mostly affects individuals aged $20-50$ years and less than $10 \%$ victims are over 65 years of age. Females have a

- Received : August 24, 2020 •Revised : September 25, 2020 •Accepted : October 7, 2020

- Address for reprints : Cheng-lin Tian

Department of Neurology, Chinese PLA General Hospital, No 28, Fuxing Road, Beijing 100853, China

Tel : +86-10-55499018, Fax : +86-10-55499018, E-mail : tianchenglin719@aliyun.com, ORCID : https://orcid.org/0000-0002-4361-9466

*Bin Lv and Feng Jing contributed equally to this study.

This is an Open Access article distributed under the terms of the Creative Commons Attribution Non-Commercial License (http://creativecommons.org/licenses/by-nc/4.0) which permits unrestricted non-commercial use, distribution, and reproduction in any medium, provided the original work is properly cited. 
3-fold greater risk of developing $\mathrm{CVT}^{29)}$. Among the risk factors for CVT incidence, heridetary thrombophilia, inflammatory disorders and cancer, pregnancy, diabetes, and oral contraceptive use are more important ${ }^{4)}$. The presentation is usually subacute as symptoms evolve over days to weeks. Commonly associated symptoms include headache, focal neurologic deficits, seizures, altered consciousness, obscuration of vision, nausea, vomiting, papilledema, cranial nerve palsies and coma ${ }^{27)}$.

Diagnosis of CVT is difficult because clinical manifestations are often nonspecific and relies mainly on neuroimaging findings which may also provide information about flow dynamics of affected area ${ }^{32)}$. Because a thrombus develops with time and can be associated with recanalization such as the chronic partially recanalized dural sinus thrombosis, neuroimaging methods can have a compromised output ${ }^{177}$. In general, a diagnosis based on T2-weighted imaging (T2WI) in combination with magnetic resonance venography (MRV) is recommended as the first line modality ${ }^{12,35)}$. Besides leaving a hyperintense signal on T2WI, a thrombus in cerebral vein or sinus may also produce a hyperintense signal on diffusionweighted imaging $(\mathrm{DWI})^{34)}$. DWI is a method of magnetic resonance imaging (MRI) technology which quantifies Brownian motion of water and is highly sensitive in detecting acute arterial strokes and distinguishing cytotoxic and vasogenic edema.

The efficiency of DWI for the diagnosis of CVT is evaluated by several authors of retrospective studies ${ }^{19-23)}$. However, the outcomes are considerably heterogenous which necessitates a systematic review of this area. The aim of the present study was to undertake a literature survey for the identifications of relevant studies and to perform a meta-analysis of important indices which can provide a refined evidence of the efficiency of DWI in diagnosing CVT.

\section{MATERIALS AND METHODS}

All analyses were based on previously published studies; therefore, no ethical approval or patient consent were required.

\section{Inclusion criteria}

The inclusion criteria were: the study - 1) evaluated the efficiency of DWI in the diagnosis of CVT; and 2) reported one or more relevant endpoint/s including the rate of hyperintense signal detection by DWI, area under receiver operator curve (AUROC) parameters for DWI utility in diagnosis CVT, and

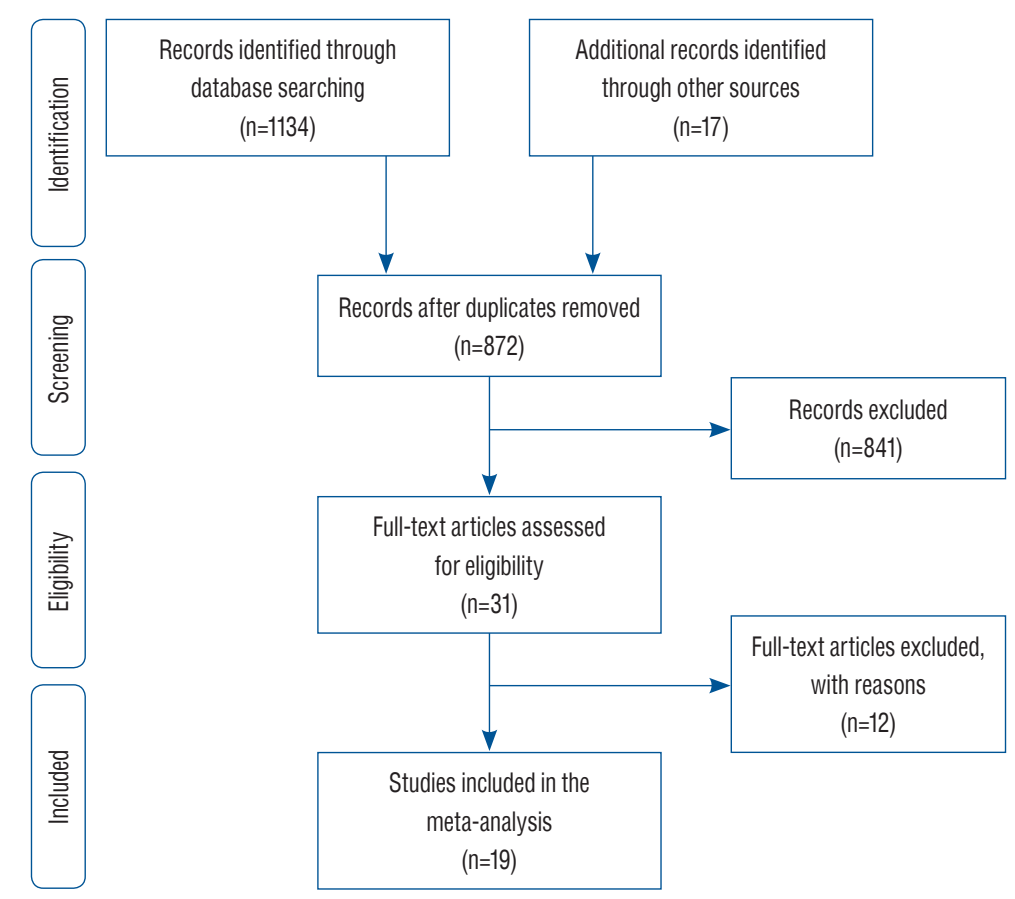

Fig. 1. A flowchart of study screening and selection process. 
apparent diffusion coefficient (ADC) values of areas with and without DWI signal in patients with CVT.

\section{Literature search}

Electronic databases (EMBASE, Google Scholar, Ovid SP, and PubMed) were searched for the acquisition of research articles reporting the outcomes of diagnostic performance/utility of DWI for CVT. Literature search was carried out by using important keywords in logical combinations. These included cerebral venous thrombosis, CVT, vein, sinus, clot, stroke, hemorrhage, edema, occlusion, magnetic resonance imaging, MRI, diffusion-weighted imaging, DWI, apparent diffusion coefficient, ADC, hyperintense signal, area under operator receiver curve (AUROC), specificity, sensitivity, diagnosis, and diagnostic accuracy. Database software suggested articles and cross references of important literary sources were also examined.

\section{Data extraction, synthesis, and statistical analysis}

Relevant data (demographic, clinical, and pathological characteristics of the patients, study design and dates, technical details of the procedures, outcome measures and outcomes) were extracted from published research articles of respective studies and were organized in specialized datasheets.

Table 1. Important characteristics of the included studies

\begin{tabular}{|c|c|c|c|c|c|c|c|c|c|c|c|}
\hline \multirow{2}{*}{ Study } & \multirow{2}{*}{$\mathrm{N}$} & \multirow{2}{*}{$\begin{array}{c}\text { Age } \\
\text { (years) }\end{array}$} & \multirow{2}{*}{$\begin{array}{c}\% \\
\text { males }\end{array}$} & \multirow{2}{*}{$\begin{array}{l}\text { Delay } \\
\text { (days) }\end{array}$} & \multirow{2}{*}{ CVT location } & \multicolumn{6}{|c|}{ Symptoms (\%) } \\
\hline & & & & & & HE & PA & NS & SE & DR & HM \\
\hline Bidar et al. ${ }^{2)}$ (2016) & 17 & $45 \pm 18$ & 24 & & SSS, SS, TS & 94 & & 47 & 24 & & \\
\hline Boukobza et al.3) (2009) & 8 & $36 \pm 8.3$ & 25 & & $\begin{array}{l}\text { Trolard, Labbe, superficial Sylvian, frontal, } \\
\text { central, precentral, small frontal, } \\
\text { midfrontal veins }\end{array}$ & 100 & & 88 & 50 & & \\
\hline Chu et al. ${ }^{6)}(2001)$ & 14 & $43 \pm 10$ & 36 & $10 \pm 9.8$ & LS, SSS, SS, TS & 79 & 50 & 71 & 50 & & 14 \\
\hline Doege et al. ${ }^{8)}(2001)$ & 6 & $46 \pm 12$ & 17 & & SSS, TS & 67 & & 83 & 33 & 50 & 50 \\
\hline Ducreux et al. ${ }^{10)}$ (2001) & 9 & $40 \pm 11$ & 0 & $1.6 \pm 1.4$ & $\begin{array}{l}\text { SSS, TS, straight sinus, temporal/Galen/ } \\
\text { internal cerebral veins }\end{array}$ & & & & & & 11 \\
\hline Favrole et al." (2004) & 28 & $33 \pm 11$ & 11 & $9.2 \pm 9.2$ & LS, SSS, deep vein system & 57 & 25 & 32 & 25 & 14 & \\
\hline Idbaih et al. ${ }^{13)}(2006)$ & 39 & $32 \pm 12$ & 10 & & LS, SSS, cortical vein, deep vein system & 100 & 18 & 0 & 26 & 10 & \\
\hline Linn et al. ${ }^{18)}(2010)$ & 13 & $42 \pm 20$ & 23 & $6.9 \pm 5.4$ & LS, SSS, SS, TS, straight sinus & 62 & & 100 & 46 & & 62 \\
\hline Lövblad et al. ${ }^{21)}(2000)$ & 18 & & 39 & & & & & & & & \\
\hline Lövblad et al. ${ }^{20)}(2001)$ & 18 & $35 \pm 14$ & 33 & & SSS, TS, bridging vein, deep vein system & 100 & & 89 & 61 & 39 & \\
\hline Lv et al. ${ }^{22)}(2020)$ & 78 & $36 \pm 12$ & 58 & $34 \pm 584$ & $\begin{array}{l}\text { SSS, STS, left TS, left SIS, left IJV, right TS, } \\
\text { right SIS, right IJV }\end{array}$ & & & & & & \\
\hline Mullins et al. ${ }^{23)}(2004)$ & 13 & $40 \pm 16$ & 38 & & $\begin{array}{l}\text { LS, SSS, SS, TS, straight sinus, jugular/Galen/ } \\
\text { internal cerebral/cortical vein }\end{array}$ & 77 & & 77 & 8 & 8 & 15 \\
\hline Sadigh et al. ${ }^{25)}(2016)$ & 36 & $47 \pm 13$ & 39 & & & & & & & & \\
\hline Sagduyu et al. ${ }^{26)}$ (2006) & 22 & $37 \pm 2.2$ & 28 & & $\begin{array}{l}\text { Parietal/internal cerebral/dorsomedial/ } \\
\text { central/temporooccipital/basal vein }\end{array}$ & 100 & & 46 & 69 & 100 & 16 \\
\hline Yii et al. ${ }^{36)}(2012)$ & 106 & $43 \pm 13$ & 27 & & $\begin{array}{l}\text { ISS, SSS, SS, TS, straight sinus, cortical veins, } \\
\text { vein of Galen }\end{array}$ & 72 & 17 & 25 & 29 & & 15 \\
\hline Yıldız et al. ${ }^{37)}(2015)$ & 13 & $35 \pm 17$ & 31 & $3.4 \pm 5.5$ & LS, SSS, cortical vein & 38 & & 38 & 15 & 8 & 7 \\
\hline Corvol et al..$^{7)}$ (1998) & 1 & 64 & 0 & 0.2 & Rolandic area & & & 100 & & & 100 \\
\hline Keller et al. ${ }^{15)}(1999)$ & 1 & 11 & 0 & 1 & Deep cerebral veins and straight sinus & & & & & & \\
\hline Wasay et al. ${ }^{33)}$ (2002) & 3 & $39.5 \pm 4$ & 0 & $1 \pm 1$ & SSS & 67 & & 67 & 33 & & 33 \\
\hline
\end{tabular}


For achieving the pooled estimates of percent DWI hyperintense signals and AUROC parameters, the meta-analysis of proportions with Freeman-Tukey double arcsine transforma-

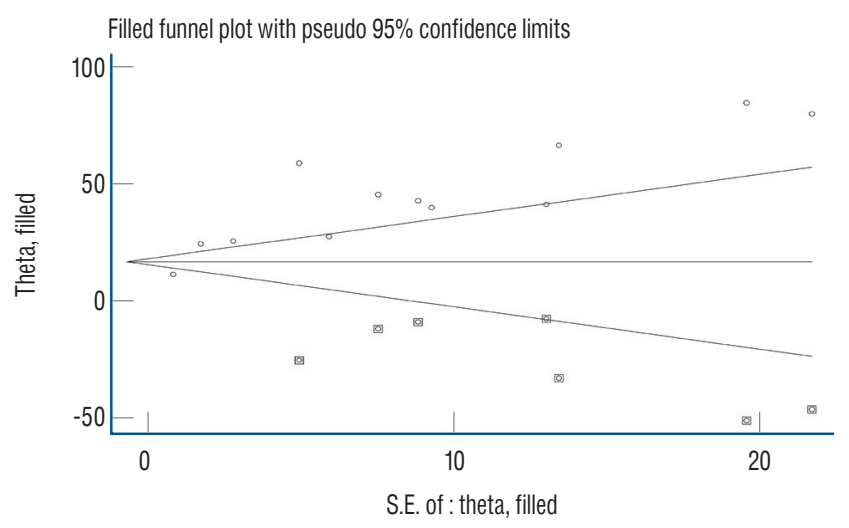

Fig. 2. A funnel plot corresponding to the meta-analysis of diffusionweighted imaging hyperintense signal rate showing the outcomes of trim and fill method of publication bias assessment. Circles show studies included in the meta-analysis whereas circles within squares show possible missing studies. S.E. : standard error. tion were performed with Stata software (version 12; Stata Corporation, College Station, TX, USA). For the evaluation of the significance of difference between DWI measured ADC of thrombosed sites and normal brain areas, a meta-analysis of mean differences was performed with RevMan software (version 5.3; Cochrane, Copenhagen, Denmark) under random effects model. Between-study inconsistency was tested with $\mathrm{I}^{2}$ index. Publication bias assessment was performed with Egger's regression asymmetry test and trim and fill method was used to estimate the number of possible missing studies.

\section{RESULTS}

Nineteen studies were included (Fig. 1). The literature search identified 872 abstracts but vast majority $(n=840)$ had to be excluded based on irrelevancy of title/abstract. Thirty-two research articles were found to have relevant text/data and were downloaded from databases. After the observance of eligibili-

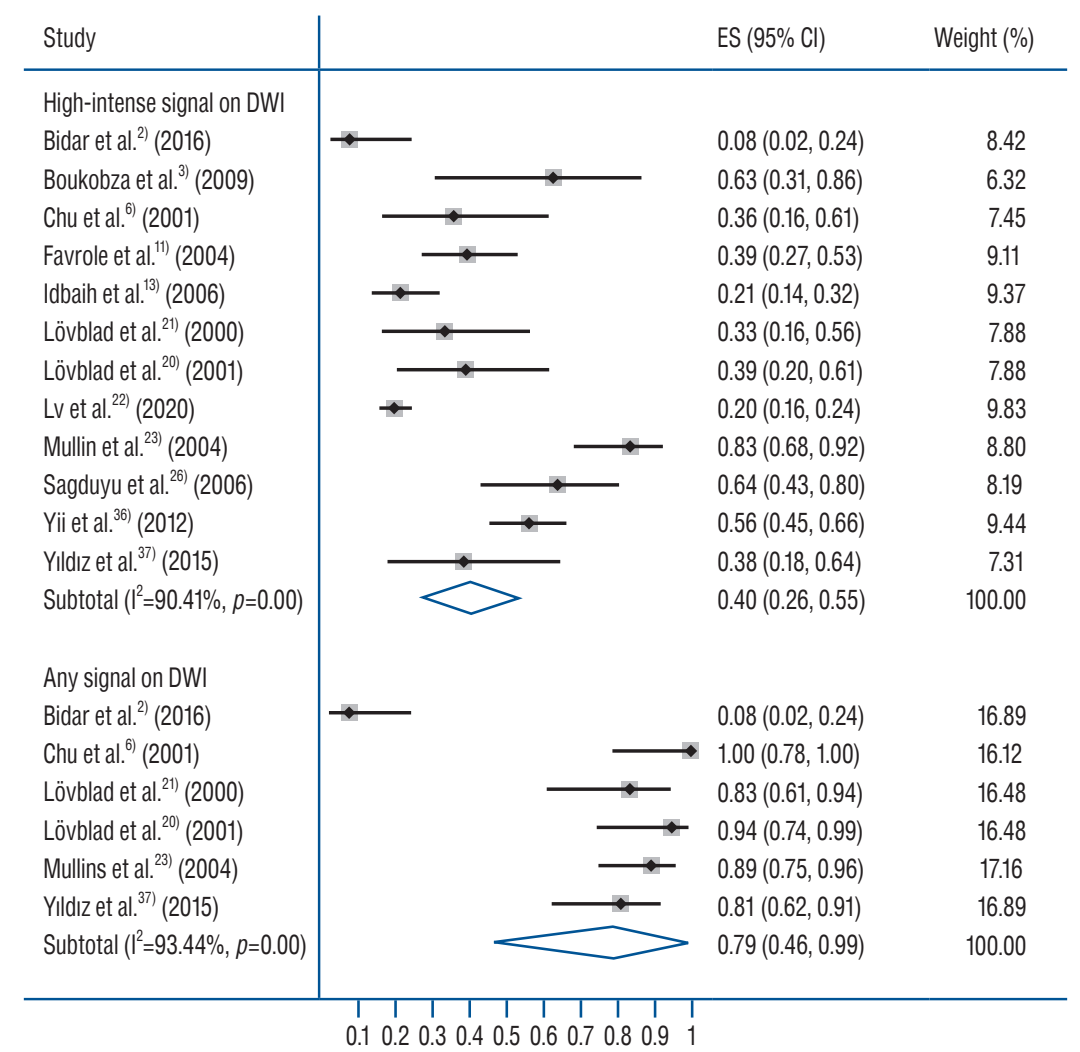

Fig. 3. A forest plot showing the overall effect size of percent rate of hyperintense signal on DWI in cerebral venous thrombosis cases. In study identities, in case of Linn et al. ${ }^{18)}$, first values are for cortical vein, and second for superior sagittal sinus. In case of Sadigh et al. ${ }^{25)}$, first and second values denote investigator 1 and 2. ES : effect size, $\mathrm{Cl}$ : confidence interval, DWI : diffusion-weighted imaging. 
ty criteria, 19 research articles were found useful for the current study. Studies that used DWI for other purposes such as characterizing cytotoxic or vasogenic edema; studies that used DWI and other diagnostic modalities but did not report re-

\begin{tabular}{|c|c|c|c|c|}
\hline Study & & & ES $(95 \% \mathrm{Cl})$ & Weight (\%) \\
\hline \multicolumn{5}{|l|}{ Speciificity } \\
\hline Linn et al. ${ }^{18)}(2010)$ & & $\longrightarrow$ & $1.00(0.77,1.00)$ & 5.71 \\
\hline Linn et al. ${ }^{18)}(2010)$ & & $\longrightarrow$ & $1.00(0.77,1.00)$ & 5.71 \\
\hline Lv et al. ${ }^{22)}(2020)$ & & $\rightarrow$ & $0.97(0.97,0.99)$ & 33.19 \\
\hline Sadigh et al. ${ }^{25)}(2016)$ & & $\rightarrow$ & $0.92(0.83,0.97)$ & 27.70 \\
\hline Sadigh et al. ${ }^{25)}(2016)$ & & $\rightarrow$ & $0.98(0.92,1.00)$ & 27.70 \\
\hline Subtotal $\left(I^{2}=0.00 \%, p=0.48\right)$ & & $\diamond$ & $0.98(0.95,1.00)$ & 100.00 \\
\hline \multicolumn{5}{|l|}{ Sensitivity } \\
\hline Bidar et al. ${ }^{2)}(2016)$ & $\leftarrow$ & & $0.00(0.00,0.18)$ & 12.01 \\
\hline Idbaih et al. ${ }^{13)}(2006)$ & $\longrightarrow$ & & $0.46(0.32,0.61)$ & 15.39 \\
\hline Lv et al. ${ }^{22)}(2020)$ & $\longrightarrow$ & & $0.35(0.25,0.46)$ & 17.32 \\
\hline Linn et al. ${ }^{18)}(2010)$ & $\longrightarrow$ & & $0.15(0.04,0.42)$ & 10.75 \\
\hline Linn et al. ${ }^{18)}(2010)$ & $\rightarrow$ & & $0.04(0.00,0.28)$ & 10.75 \\
\hline Sadigh et al. ${ }^{25)}(2016)$ & $\longrightarrow$ & & $0.25(0.16,0.36)$ & 16.89 \\
\hline Sadigh et al. ${ }^{25)}(2016)$ & $\longrightarrow$ & & $0.28(0.18,0.40)$ & 16.89 \\
\hline Subtotal $\left(I^{2}=77.49 \%, p=0.00\right)$ & & & $0.22(0.11,0.34)$ & 100.00 \\
\hline \multicolumn{5}{|l|}{ AUC } \\
\hline Sadigh et al. ${ }^{25)}(2016)$ & $\rightarrow$ & & $0.58(0.42,0.73)$ & 26.55 \\
\hline Sadigh et al. ${ }^{25)}(2016)$ & $\rightarrow$ & & $0.59(0.39,0.77)$ & 16.36 \\
\hline Lv et al. ${ }^{22)}(2020)$ & $\longrightarrow$ & & $0.67(0.56,0.76)$ & 57.09 \\
\hline Subtotal $\left(I^{2}=, p=\right)$ & & & $0.63(0.55,0.71)$ & 100.00 \\
\hline \multicolumn{5}{|l|}{ PPV } \\
\hline Linn et al. ${ }^{18)}(2010)$ & & 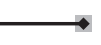 & $1.00(0.77,1.00)$ & 12.80 \\
\hline Linn et al. ${ }^{18)}(2010)$ & & $\rightarrow$ & $1.00(0.77,1.00)$ & 12.80 \\
\hline Lv et al. ${ }^{22)}(2020)$ & & $\rightarrow$ & $0.94(0.86,0.97)$ & 74.41 \\
\hline Subtotal $\left(I^{2}=, p=\right)$ & & $\diamond$ & $0.97(0.92,1.00)$ & 100.00 \\
\hline \multicolumn{5}{|l|}{ NPV } \\
\hline Linn et al. ${ }^{18)}(2010)$ & & & $0.46(0.23,0.71)$ & 12.80 \\
\hline Linn et al. ${ }^{18)}(2010)$ & & & $0.62(0.36,0.82)$ & 12.80 \\
\hline Lv et al..$^{22)}(2020)$ & 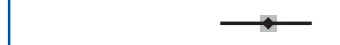 & & $0.62(0.49,0.70)$ & 74.41 \\
\hline Subtotal $\left(I^{2}=, p=\right)$ & & & $0.59(0.49,0.69)$ & 100.00 \\
\hline
\end{tabular}

Fig. 4. A forest plot showing the pooled sensitivity and specificity values in diagnosing cerebral venous thrombosis by diffusion-weighted imaging. ES : effect size, $\mathrm{Cl}$ : confidence interval, AUC : area under curve, PPV : positive predictive value, NPV : negative predictive value.

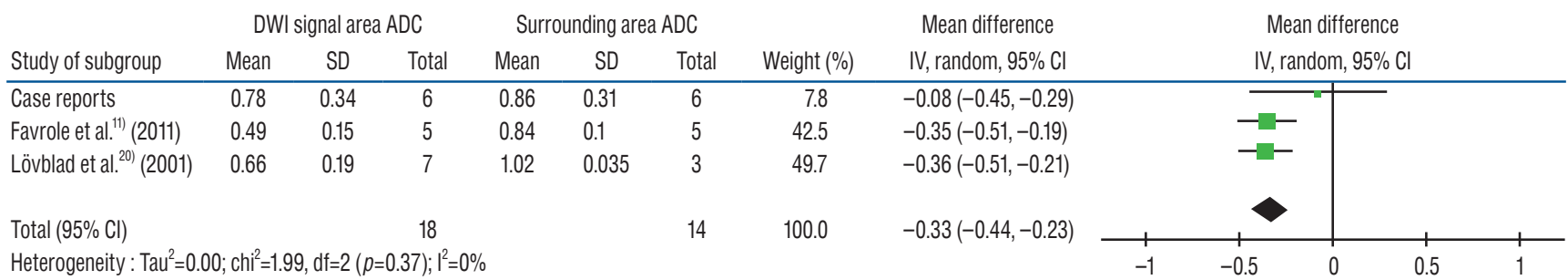

Test for overall effect : $Z=6.35(p<0.00001)$

Fig. 5. A forest plot showing the mean difference between ADC values in thrombosed areas and surrounding areas of patients with cerebral venous thrombosis. DWI : diffusion-weighted imaging, $\mathrm{ADC}$ : apparent diffusion coefficient, $\mathrm{SD}$ : standard deviation, $\mathrm{Cl}$ : confidence interval. 
sults for each method separately; studies published in a nonEnglish language; and review articles were excluded.

Among the included studies, 16 were retrospective in desig $\mathrm{ns}^{2,3,6,8,10,11,13,18,20-23,25,26,36,37)}$ and three were the case reports ${ }^{7,15,33)}$. In all, 443 patients with CVT were subjected to DWI examinations in these studies. Total number of CVTs studied was 856. Important characteristics of the included studies are presented in Table 1. Study of a funnel plot corresponding to the meta-analysis of pooled incidence of hyperintense signal on DWI indicated the possibility of some missing studies (Fig. 2). Egger's regression asymmetry test also showed significant publication bias (coefficient : 4.46 [95\% confidence interval (CI), 2.31 to 6.60$] ; p=0.001$ ).

Age of these patients was 40.1 years (95\% CI, 33.1 to 43.1 ) and $28 \%$ (95\% CI, 18 to 38$)$ of these patients were male. Delay time from onset of symptoms to DWI was 4.61 days $(95 \%$ CI, 2.3 to 6.9$)$. Major symptoms in these patients were: headache $76.4 \%$ (95\% CI, 62.6 to 90.3), neurological deficits 71.6\% (95\% CI, 56.0 to 87.2 ), seizures (33.6\% [ $95 \%$ CI, 24.7 to 42.5$]$ ), hemiparesis $32.3 \%$ (95\% CI, 25.2 to 39.3), papilledema $27.2 \%$ (95\% CI, 19.3 to 35.1), and drowsiness (21.0\% [95\% CI, 13.8 to 28.3]).

Eighty-two percent of cerebral thromboses were found in sinuses and $18 \%$ in veins. Among the sinuses, the incidence of thrombosis was $28 \%$ in superior sagittal sinus, $37 \%$ in lateral/ transverse sinus, $13 \%$ in sigmoid sinus, $4 \%$ in straight sinus, and $0.74 \%$ in inferior sagittal sinus. Among the cortical veins, the incidence of thrombosis was $0.55 \%$ in frontal vein, $0.37 \%$ in Trolard vein, $0.37 \%$ in Labbe vein, and $0.2 \%$ in superficial Sylvian vein. Within the deep cerebral veins, the incidence of thrombus was $1 \%$ in vein of Galen and $0.56 \%$ in internal cerebral vein. Moreover, the thrombus incidence was $0.37 \%$ in jugular vein, $0.2 \%$ in central vein and $0.2 \%$ in precentral vein.

Hyperintense signals on DWI were detected in 40\% (95\% CI, 26 to 55) of the patients with CVT (Fig. 3). However, any signal of clinical interest on DWI was found in 79\% (95\% CI, 46 to 99) of the patients. The sensitivity of DWI in the diagnosis of CVT was $22 \%$ (95\% CI, 11 to 34). However, the specificity of DWI for detecting CVT was 98\% (95\% CI, 95 to 100) (Fig. 4).

ADC findings of the including studies were much heterogeneous. The range of ADC $\left(\times 10^{-3} \mathrm{~mm}^{2} / \mathrm{s}\right)$ values in the DWI signal areas noted by the individual studies were $0.25-1.2^{23}$, $0.32-0.86^{6}, 0.33-1.74^{10)}, 0.49 \pm 0.15$ (standard deviation) ${ }^{11}$, $0.65-0.79^{20)}$, and $0.81-1.3^{8)}$. In general, the ADC values were lower in DWI signal areas than in surrounding non-CVT areas (mean difference $-0.33 \times 10^{-3} \mathrm{~mm}^{2} / \mathrm{s}[95 \% \mathrm{CI},-0.44$ to $-0.23] ; p<0.00001$; Fig. 5).

\section{DISCUSSION}

In a sample population of patients with CVT who underwent DWI studies, we have found that the proportion of patients with CVT in whom hyperintense signals were detected on DWI was approximately $40 \%$. Only a few studies reported the AUROC data, based on which the sensitivity of DWI in detecting a CVT was only $22 \%$ whereas the specificity was $98 \%^{2,13,18,22,25)}$. There was a wider range of ADC values for DWI signal areas but generally it was lower in thrombosed areas than in surrounding tissues.

Currently, the MRI is routinely used in patients suspected for the presence of CVT by using different MRI sequences. Although, we have observed that hyperintense signal on DWI is associated with low sensitivity to detect CVT, however, the hyperintense signal on DWI had high specificity for CVT. It is suggested that DWI can provide an additional clue for the diagnosis of CVT which could be important in clinically unsuspected patients ${ }^{37}$. By using DWI, Favrole et al. ${ }^{11)}$ detected 20 occluded veins or sinuses in 12 patients $(41 \%)$ with recent CVT and suggested that the presence of hyperintense signal on DWI in occluded veins at the time of diagnosis might be predictive of a low rate of vessel recanalization 2 or 3 months later. They also suggested that the movements of water molecules are restricted within the venous clot according to the stage of CVT formation ${ }^{11}$. Using diffusion-tensor imaging for 77 CVTs in 33 children, Wagner et al. ${ }^{31)}$ found restricted diffusion patterns in $38 \%$ of thromboses.

We have found that the proportion of patients with CVT for whom DWI hyperintense signals were detected was approximately $40 \%$. The range was from $8 \%$ to $83 \%$ in the individual studies which contributed to a high statistical heterogeneity in this pooled analysis. Signal intensity on DWI mainly depends on restricted rates of diffusion. Compared with the normal white matter, stable but reduced diffusion has been observed in hyperacute, acute, and early subacute hematomas containing hemoglobin within intact red blood cells ${ }^{1,14,28)}$. A thrombus in the vein can be differentiated from an intracerebral hematoma by the absence of extracellular fluid due to which 
thrombus exhibits highly restricted diffusion that can result in more intense signal on DWI ${ }^{22}$.

The MRI intensity of venous thrombus varies according to time of imaging from the onset of thrombus formation. This may also affect the results of DWI to show high signal intensity with low ADC due to restricted diffusion. Especially if symptoms are subtle and the progression of thrombus is not uniform, the onset of thrombus formation cannot be detected accurately always which may lead to a low sensitivity of this method. Diagnosis of a thrombus in the cerebral veins can also be influenced by the paramagnetic effect of deoxyhemoglobin in blood ${ }^{16}$. The latest AHA/ASA scientific statement recommends that gradient echo T2 susceptibility-weighted imaging with MRI should be used to improve the accuracy of CVT diagnosis $^{27)}$.

Use of DWI can be more valuable in discriminating the types of edema, in the assessment of tissue viability, in the detection of subclinical abnormalities, and in facilitation of basic imaging research related to the pathophysiology of $\mathrm{CVT}^{6}$. It has also been suggested that DWI may provide an additional clue to CVT diagnosis in clinically unsuspected patients after standard MRI scans but without sensitive MRI sequences such as contrast enhanced MRV or T2-weighted gradient recalled echo. Careful examination of cortical surface on diffusion MRI for clot signal or clot susceptibility signal can give additional information when CVT is not suspected on routine T1 or $\mathrm{T} 2$ or fluid-attenuated inversion recovery sequence ${ }^{37)}$. The presence of hyperintense signal on DWI has also been found to be predictive of clinical deterioration during hospital stay ${ }^{31}$.

ADC values were quite heterogenous in DWI signal areas among the included studies and less data were available to study ADC patterns comparatively. Generally, the ADC values were lower in DWI signal areas in comparison with surrounding areas. Lower ADC values are usually associated with pathological conditions including cerebrovascular events ${ }^{5,9,24)}$. Moreover, ADC values change with time. In atypical ischemic event in brain, the ADC start decreasing from first hour of event to reach minimal levels at 24 hours after the onset of event and then start rising to become higher than surrounding normal tissue after 3 days of onset ${ }^{2}$. In cerebral hemorrhage patients too, a correlation is found between the signal intensity ratio on DWI with that of T2WI, but there existed no correlation between signal intensity and $\mathrm{ADC}^{28)}$.

\section{CONCLUSION}

This meta-analytical review suggests that DWI has low diagnostic efficiency and thus has a high risk of missing many CVT cases but may have supporting and exploratory roles. Although, hyperintense signals can be found at sites of thrombosis on DWI in at least some patients with CVT, the DWI may be more useful in differentiating CVT from intravenous non-thrombotic tissue as well as subclinical abnormalities. However, more data will be required to precisely evaluate DWI performance for CVT detection in general or for a subgroup of patients.

\section{CONFLICTS OF INTEREST}

No potential conflict of interest relevant to this article was reported.

\section{INFORMED CONSENT}

This type of study does not require informed consent.

\section{AUTHOR CONTRIBUTIONS}

\author{
Conceptualization : CT \\ Data curation : FJ \\ Formal analysis : BL, FJ \\ Funding acquisition : JW \\ Methodology : JL \\ Project administration : SY \\ Visualization : XC \\ Writing - original draft : XL \\ Writing - review \& editing : BL
}

\section{ORCID}

$\begin{array}{ll}\text { Bin Lv } & \text { https://orcid.org/0000-0001-9858-8778 } \\ \text { Feng Jing } & \text { https://orcid.org/0000-0002-3532-2013 } \\ \text { Cheng-lin Tian } & \text { https://orcid.org/0000-0002-4361-9466 } \\ \text { Jian-chao Liu } & \text { https://orcid.org/0000-0001-5647-3518 } \\ \text { Jun Wang } & \text { https://orcid.org/0000-0001-7671-8789 }\end{array}$


Xiang-yu Cao

https://orcid.org/0000-0003-0950-9674

Xin-feng Liu

Sheng-yuan Yu

https://orcid.org/0000-0001-5551-0022

https://orcid.org/0000-0003-4992-0521

\section{References}

1. Atlas SW, DuBois P, Singer MB, Lu D : Diffusion measurements in intracranial hematomas: implications for MR imaging of acute stroke. AJNR Am J Neuroradiol 21 : 1190-1194, 2000

2. Bidar $F$, Faeghi $F$, Ghorbani $A$ : Assessment of cerebral venous sinus thrombosis using T2 $\left({ }^{*}\right)$-weighted gradient echo magnetic resonance imaging sequences. Iran J Neurol 15 : 96-99, 2016

3. Boukobza M, Crassard I, Bousser MG, Chabriat $H$ : MR imaging features of isolated cortical vein thrombosis: diagnosis and follow-up. AJNR Am J Neuroradiol 30 : 344-348, 2009

4. Chiewvit P, Piyapittayanan $S$, Poungvarin $N$ : Cerebral venous thrombosis: diagnosis dilemma. Neurol Int 3 : e13, 2011

5. Choi SY, Chang YW, Park HJ, Kim HJ, Hong SS, Seo DY : Correlation of the apparent diffusion coefficiency values on diffusion-weighted imaging with prognostic factors for breast cancer. Br J Radiol 85 : e474e479, 2012

6. Chu K, Kang DW, Yoon BW, Roh JK : Diffusion-weighted magnetic resonance in cerebral venous thrombosis. Arch Neurol 58 : 1569-1576, 2001

7. Corvol JC, Oppenheim C, Manaï R, Logak M, Dormont D, Samson Y, et al. : Diffusion-weighted magnetic resonance imaging in a case of cerebral venous thrombosis. Stroke 29 : 2649-2652, 1998

8. Doege CA, Tavakolian R, Kerskens CM, Romero BI, Lehmann R, Einhäupl $\mathrm{KM}$, et al. : Perfusion and diffusion magnetic resonance imaging in human cerebral venous thrombosis. J Neurol 248 : 564-571, 2001

9. Drake-Pérez M, Boto J, Fitsiori A, Lovblad K, Vargas Ml : Clinical applications of diffusion weighted imaging in neuroradiology. Insights Imaging 9 : 535-547, 2018

10. Ducreux D, Oppenheim C, Vandamme X, Dormont D, Samson Y, Rancurel $G$, et al. : Diffusion-weighted imaging patterns of brain damage associated with cerebral venous thrombosis. AJNR Am J Neuroradiol 22 : 261-268, 2001

11. Favrole P, Guichard JP, Crassard I, Bousser MG, Chabriat H : Diffusionweighted imaging of intravascular clots in cerebral venous thrombosis. Stroke 35 : 99-103, 2004

12. Guenther G, Arauz A : Cerebral venous thrombosis: a diagnostic and treatment update. Neurologia 26 : 488-498, 2011

13. Idbaih A, Boukobza M, Crassard I, Porcher R, Bousser MG, Chabriat $H$ : MRI of clot in cerebral venous thrombosis: high diagnostic value of susceptibility-weighted images. Stroke 37 : 991-995, 2006

14. Kang BK, Na DG, Ryoo JW, Byun HS, Roh HG, Pyeun YS : Diffusionweighted MR imaging of intracerebral hemorrhage. Korean J Radiol 2 : 183-191, 2001

15. Keller E, Flacke S, Urbach H, Schild HH : Diffusion- and perfusion- weighted magnetic resonance imaging in deep cerebral venous thrombosis. Stroke 30 : 1144-1146, 1999

16. Leach JL, Strub WM, Gaskill-Shipley MF : Cerebral venous thrombus signal intensity and susceptibility effects on gradient recalled-echo MR imaging. AJNR Am J Neuroradiol 28 : 940-945, 2007

17. Leach JL, Wolujewicz M, Strub WM : Partially recanalized chronic dural sinus thrombosis: findings on MR imaging, time-of-flight MR venography, and contrast-enhanced MR venography. AJNR Am J Neuroradiol 28 : 782-789, 2007

18. Linn J, Michl S, Katja B, Pfefferkorn T, Wiesmann M, Hartz S, et al. : Cortical vein thrombosis: the diagnostic value of different imaging modalities. Neuroradiology 52 : 899-911, 2010

19. Linn J, Pfefferkorn T, Ivanicova K, Müller-Schunk S, Hartz S, Wiesmann $M$, et al. : Noncontrast $C T$ in deep cerebral venous thrombosis and sinus thrombosis: comparison of its diagnostic value for both entities. AJNR Am J Neuroradiol 30 : 728-735, 2009

20. Lövblad KO, Bassetti C, Schneider J, Guzman R, El-Koussy M, Remonda L, et al. : Diffusion-weighted $\mathrm{mr}$ in cerebral venous thrombosis. Cerebrovasc Dis 11 : 169-176, 2001

21. Lövblad KO, Bassetti C, Schneider J, Ozdoba C, Remonda L, Schroth $G$ : Diffusion-weighted MRI suggests the coexistence of cytotoxic and vasogenic oedema in a case of deep cerebral venous thrombosis. Neuroradiology 42 : 728-731, 2000

22. Lv B, Tian CL, Cao XY, Liu XF, Wang J, Yu SY : Role of diffusion-weighted imaging in the diagnosis of cerebral venous thrombosis. J Int Med Res $48: 300060520933448,2020$

23. Mullins ME, Grant PE, Wang B, Gonzalez RG, Schaefer PW : Parenchymal abnormalities associated with cerebral venous sinus thrombosis: assessment with diffusion-weighted MR imaging. AJNR Am J Neuroradiol 25 : 1666-1675, 2004

24. Mussi TC, Martins T, Tachibana A, Mousessian PN, Baroni RH : Objective value on apparent diffusion coefficient (ADC) map to categorize the intensity of diffusion-weighted imaging (DWI) restriction for prostate cancer detection on multiparametric prostate MRI. Int Braz J Urol 44 : 882-891, 2018

25. Sadigh G, Mullins ME, Saindane AM : Diagnostic performance of MRI sequences for evaluation of dural venous sinus thrombosis. AJR Am J Roentgenol 206 : 1298-1306, 2016

26. Sagduyu A, Sirin H, Mulayim S, Bademkiran F, Yunten N, Kitis O, et al. : Cerebral cortical and deep venous thrombosis without sinus thrombosis: clinical MRI correlates. Acta Neurol Scand 114 : 254-260, 2006

27. Saposnik G, Barinagarrementeria F, Brown RD Jr, Bushnell CD, Cucchiara $B$, Cushman $M$, et al. : Diagnosis and management of cerebral venous thrombosis: a statement for healthcare professionals from the American Heart Association/American Stroke Association. Stroke 42 : 1158-1192, 2011

28. Silvera S, Oppenheim C, Touzé E, Ducreux D, Page P, Domigo V, et al. : Spontaneous intracerebral hematoma on diffusion-weighted images: Influence of T2-shine-through and T2-blackout effects. AJNR Am J Neuroradiol 26 : 236-241, 2005

29. Silvis SM, de Sousa DA, Ferro JM, Coutinho JM : Cerebral venous throm- 
bosis. Nat Rev Neurol 13 : 555-565, 2017

30. Stam J : Thrombosis of the cerebral veins and sinuses. N Engl J Med $352: 1791-1798,2005$

31. Wagner MW, Bosemani T, Oshmyansky A, Poretti A, Huisman TA : Neuroimaging findings in pediatric cerebral sinovenous thrombosis. Childs Nerv Syst 31 : 705-712, 2015

32. Wasay $M$, Azeemuddin $M$ : Neuroimaging of cerebral venous thrombosis. J Neuroimaging 15 : 118-128, 2005

33. Wasay M, Bakshi R, Bobustuc G, Dubey N, Cheema Z, Dai A : Diffusionweighted magnetic resonance imaging in superior sagittal sinus thrombosis. J Neuroimaging 12 : 267-269, 2002

34. Washida K, Kowa H, Tsuji Y, Sekiguchi K, Kanda F, Toda T : Multiple deep white matter hyperintense lesions on diffusion-weighted imaging: early sign of straight sinus thrombosis. J Stroke Cerebrovasc Dis 25 : e131-e133, 2016

35. Weimar C, Masuhr F, Hajjar K : Diagnosis and treatment of cerebral venous thrombosis. Expert Rev Cardiovasc Ther 10 : 1545-1553, 2012

36. Yii IY, Mitchell PJ, Dowling RJ, Yan B : Imaging predictors of clinical deterioration in cerebral venous thrombosis. J Clin Neurosci 19 : 15251529, 2012

37. Yıldız ME, Ozcan UA, Turk A, Ulus OS, Erzen C, Dinçer A : Diffusionweighted MR imaging findings of cortical vein thrombosis at $3 \mathrm{~T}$. Clin Neuroradiol 25 : 249-256, 2015 